\title{
Correction to: Self-referential propositions
}

\section{Bruno Whittle ${ }^{1}$}

\section{Correction to: Synthese (2017) 194:5023-5037 https://doi.org/10.1007/s11229-016-1191-0}

Unfortunately, there is a mistake in line 10 of Section 1.2. The correct reference should read:

As Kripke pointed out, we can produce one simply by baptizing the string 'Jack is short': Jack (1975, p. 693).

The original article can be found online at https://doi.org/10.1007/s11229-016-1191-0.

$凶$ Bruno Whittle

bruno.whittle@glasgow.ac.uk

1 Department of Philosophy, University of Glasgow, Glasgow G12 8QQ, UK 